\title{
Intimate partner sexual violence and risk for femicide, suicidality and substance use among women in antenatal care and general out-patients in Thailand
}

\author{
Supa Pengpid ${ }^{1,2}$, Karl Peltzer ${ }^{2,3^{*}}$ (D), Orapin Laosee ${ }^{1}$ and Kawinarat Suthisukon ${ }^{1}$
}

\begin{abstract}
Background: Little is known about the occurrence and health consequences of intimate partner sexual assault. The aim of this study was to assess the prevalence and correlates of sexual assault in the context of intimate partner violence (IPV) in Thailand.

Methods: In a cross-sectional survey adult female participants were systematically screened (self-administered or interview administered) for IPV in antenatal care and general outpatient clinics in nine randomly selected hospitals in two provinces in the central region. Measures included the Abuse Assessment Screen, Severity of Violence Against Women Scale, Danger assessment and suicidal behaviour.

Results: From 14,288 women screened, 1.5\% were positive for IPV and 207 participated in the study. The mean age of the study participants was 26.8 years $(S D=9.3)$. Fifty-seven women, $27.5 \%$ of the sample, reported sexual assault, one or more times, during the relationship in the past 12 months. Most reported some form of psychological abuse (82.1\%), physical violence (67.1\%) and danger (72.0\%). In all, 21.3\% reported psychological, physical and sexual violence. Bivariate analyses found that older age, being recruited in the general out-patient department, greater number of children, high psychological abuse, high physical violence, danger and suicidal behaviour in the past 12 months were associated with sexual assault. In multivariable backward conditional logistic regression physical violence $(\mathrm{OR}=5.32$, $\mathrm{Cl}=2.52-11.24)$ and suicidal behaviour $(\mathrm{OR}=3.28, \mathrm{Cl}=1.37-7.83)$ were found to be associated with sexual assault.

Conclusions: The study found a moderate rate of sexual assault in intimate violent partner relationships and those sexual assaults are more likely to co-occur with physical intimate partner violence and suicidal behaviour. This knowledge may be helpful in the detection and management of sexual assault in intimate violent partner relationships of women in health care settings in Thailand.
\end{abstract}

Keywords: Sexual assault, Psychological abuse, Physical violence, Danger, Intimate partner, Thailand

\section{Background}

"Intimate partner violence refers to any behaviour within an intimate relationship that causes physical, psychological or sexual harm to those in that relationship" [1]. The prevalence and health effects of physical intimate partner violence (IPV) have been well documented,

\footnotetext{
* Correspondence: kpeltzer@hsrc.ac.za

${ }^{2}$ Department of Research \& Innovation, University of Limpopo, Sovenga 0727, South Africa

${ }^{3} \mathrm{HIV} / \mathrm{AIDS} / \mathrm{STI} / \mathrm{and} \mathrm{TB}(\mathrm{HAST})$, Human Sciences Research Council, Pretoria 0001 , South Africa

Full list of author information is available at the end of the article
}

while less is known about the occurrence and health consequences of sexual IPV [2]. Globally, in studies (as reviewed in [3]) that measured sexual assault separately from physical violence, a high proportion of women (40-68\%) had experienced both physical and sexual violence. Further, studies (as reviewed in [3]) consistently showed that compared to women who experienced physical intimate partner violence (only), women with sexual partner violence or sexual and physical partner violence had higher levels of physical and emotional intimate partner violence, had more risk factors for 
femicide, were more likely to report threatening or attempting suicide, used alcohol or substances and were not living with the abuser.

Among six European countries women in an antenatal care setting reported $2.7 \%$ emotional abuse in the past 12 months, $2.2 \%$ physical abuse, $0.4 \%$ sexual abuse and $3.8 \%$ any abuse in the past 12 months [4]. Past year intimate partner violence during pregnancy was $2.0 \%$ in Cambodia, $0.4 \%$ in the Philippines, $1.2 \%$ in Japan and $3.8 \%$ in rural and $4.2 \%$ in urban Thailand [5]. Other local surveys in Thailand found among pregnant women that $4.8 \%$ had experienced physical intimate partner violence during pregnancy and $4.8 \%$ sexual violence in the past 12 months [6], and in another study Saito et al. [7] found among prenatal women that $26.6 \%$ were exposed to overall threats and acts of physical violence during their current pregnancy, and Saito et al. [8] found among post-partum women that overall $9.5 \%$ were exposed to threats and physical violence and $11.3 \%$ sexual violence. There is a lack of studies on the prevalence and correlates of sexual assault in the context of intimate partner violence in Thailand.

The aim of this study was to assess the prevalence and correlates of sexual assault in the context of intimate partner violence in a sample of women attending antenatal care or general out-patient hospital services in Thailand.

\section{Methods}

\section{Sample and procedure}

Adult female participants were systematically screened for intimate partner violence in nine randomly selected hospitals (antenatal care and out-patient clinics) in Central Thailand. A recruiter to determine eligibility approached all women who presented to a study site for a health care visit using the Abuse Assessment Screen [9]. The screen included two questions, "1) During the last 12 months, have you been pushed, shoved, slapped, hit, kicked or otherwise physically hurt by someone? 2) During the last 12 months, have you been forced into sexual activities by someone?" [9] Response options were "yes" or "no", and if yes, by whom. Written informed consent was obtained from all study participants who met the following inclusion criteria: (1) be female, (2) be 18 years of age and older, (3) have experienced IPV in the past 12 months, and (4) willingness to provide informed consent. Following an informed consent procedure, the interviewer verbally administered a questionnaire in Thai language in a private room without the partner or other individuals being present. All instruments were translated from English into Thai using standard backward and forward methods. The trained research assistants adhered strictly to the research principles of conducting research on violence against women [10], such as the safety of respondents and the researcher, and protecting confidentiality to ensure women's safety and data quality. Participants were assured that their responses would be confidential and anonymous and that refusal would not jeopardise their management. For further management, women were referred to the hospital One-Stop Crisis Centre (OSCC). The study was conducted from November 2014 to October 2015.

\section{Measures}

Intimate partner violence was assessed with 46 items of the Severity of Violence Against Women Scale (SVAWS); 19 items on threats of physical violence (scores 0 to 57), 21 items on physical assault ( 0 to 81 scores) and 6 items on sexual violence (scores 0 to 18 ) in the past 12 months $[11,12]$. The SVAWS has been pilot tested for face validity in Thailand before [13]. (Cronbach alpha was 0.96).

The Danger Assessment Scale (15 items) was used to measure risk factors associated with homicide in situations including abuse in the past 12 months [14]; the sexual assault item was deleted from this scale, as it is covered by the SVAWS, so that the possible total range of scores was from 0 to 14 . (Cronbach alpha was 0.88 .

Suicidal behaviour was measured in terms of women reporting threatening or trying to commit suicide within the last 12 months [2].

The Alcohol Use Disorder Identification Test- Consumption (AUDIT-C) [15] was used to classify hazardous alcohol use or having an active alcohol use disorder [15]. (Cronbach alpha was 0.90).

Sociodemographic items assessed included, age, marital status, living with partner, education, number of children, employment status and subjective economic household situation.

\section{Data analysis}

The data were analysed using IBM SPSS (version 22.0) (Chicago, IL, USA). Frequencies, means, standard deviations, were calculated to describe the sample. Data were checked for normality distribution and outliers, and for non-normally distributed data, non-parametric tests were used. For the logistic regression analysis, two groups were formed: 1) women who were sexually assaulted and 2) women who were never sexually assaulted by the intimate partner in the past 12 months. Adjusted odds ratios and 95\% confidence intervals were calculated from multiple backward conditional logistic regression models to examine associations between sexual assault and demographic and partnership characteristics, other types of intimate partner violence, alcohol use and suicidal behaviour [3].

\section{Results}

\section{Sample characteristics}

In all, 14,288 women (3779 in antenatal care and 10,409 in general out-patient clinics) in nine hospitals were screened for IPV over a period of 9 months. From the 
14,288 women screened, 212 screened positive for IPV (1.5\%), of which five refused to be part of the study, so that the final sample was 207. The mean age of the study participants was 26.8 years $(\mathrm{SD}=9.3)$. All were Thai, they had on average 1.1 children $(\mathrm{SD}=1.0)$, and most $(73.8 \%)$ had a secondary or higher education. Most (63.2\%) of the women had a good economic household situation ("We have most of the important things but few luxury goods." Or "Some money for extra things such as going away for holidays and luxury goods.").

Regarding participants' relationships with their abusive partners, $87.0 \%$ were married or cohabiting, and $84.4 \%$ were living with their abusive partner at the time of the assessment and in $8.7 \%$ of the cases they had left their partner in the past 12 months. Fifty-seven women, $27.5 \%$ of the sample, reported sexual assault, one or more times, during the relationship in the past 12 months. Most reported some form of psychological abuse (82.1\%), physical violence (67.1\%) and danger (72.0\%). In all, 21.3\% reported psychological, physical and sexual violence. Thirty six (17.6\%) of the women reported threatening or trying to commit suicide in the past 12 months and 23.3\% have risky alcohol use in the past 12 months. More than a quarter $(27.5 \%)$ reported sexual violence in the past 12 months (see Table 1).

\section{Types and frequency of sexual assault}

More than half $(57.9 \%)$ of the women reporting sexual assault had been forced to have sex against their will and $87.7 \%$ had been demanded to have sex whether they wanted to or not in the past 12 months (see Table 2).

\section{Sexual assault and danger}

Tables 3 shows the frequency of each risk factor for danger scores, along with the relative risk for sexually assaulted compared to non-sexually assaulted women. Sexually assaulted women reported statistically significant more risk factors of danger compared to not sexually assaulted women $(P<0.001)$. Regarding danger items, increase in severity or frequency of physical violence (Relative Risk Ratio, $R R R=1.47$, 95\% Confidence Interval, $\mathrm{CI}=1.14-1.91)$, the use of a weapon $(R R R=1.92, C I=1.18-3.13)$, threat to kill $(R R R=$ $1.35, \mathrm{CI}=1.08-1.70)$, choking $(\mathrm{RRR}=1.42, \mathrm{CI}=1.04-1.93)$, violently and constantly jealous $(\mathrm{RRR}=1.26, \mathrm{CI}=1.10$ 1.68 ), control of daily activities ( $R R R=1.59, C I=1.18$ $2.13)$, spy on you ( $R R R=1.48, \mathrm{CI}=1.17-1.87$ ), and having been beaten while pregnant $(\mathrm{RRR}=1.28, \mathrm{CI}=1.00-1.65$ ) were found to be more frequent among sexually assaulted compared to non-sexually assaulted women (see Table 3 ).

\section{Logistic regression analyses of sexual assault}

Bivariate analyses found that older age (Odds Ratio, OR $=1.04, \mathrm{CI}=1.00-1.07)$, being recruited in the general out-patient department $\quad(\mathrm{OR}=2.57, \quad \mathrm{CI}=1.37-5.83)$, greater number of children $(\mathrm{OR}=1.57, \mathrm{CI}=1.14-2.15)$, high psychological abuse $(\mathrm{OR}=5.83, \mathrm{CI}=2.67-12.74)$, high physical violence $(\mathrm{OR}=4.55, \mathrm{CI}=2.13-9.75)$, high danger $(\mathrm{OR}=8.49, \mathrm{CI}=3.75-19.18)$ and suicidal behaviour in the past 12 months $(\mathrm{OR}=4.58, \mathrm{CI}=2.16-9.74)$ were associated with sexual assault. In multivariable logistic regression high psychological violence $(\mathrm{OR}=3.42$ (1.07-11.01) was statistically significant and high physical violence $(\mathrm{OR}=2.42, \mathrm{CI}=0.95-6.16)$ and suicidal behaviour $(\mathrm{OR}=2.62, \mathrm{CI}=0.94-7.31)$ approached statistical significance with sexual assault (see Table 4).

\section{Discussion}

This is the first study in Thailand screening a large sample of women for intimate partner violence and provides prevalence rates of different types of intimate partner violence including sexual assault in a sample of women attending a health care setting service. From 14,288 women screened in antenatal care and in general outpatient clinics in hospitals, $1.5 \%$ screened positive for the past 12 months intimate partner violence. This prevalence seems to be comparable with similar studies in similar settings $(2.2 \%$ physical abuse in six European countries) [4] and Asian countries (ranging from 1.2\% in Japan to $4.0 \%$ in Thailand) [5]. In some local surveys in Thailand the prevalence of past 12 month intimate partner violence ranged from 4.8 to $26.6 \%$ [6-8]. One possible explanation for the higher prevalence in the latter surveys is that detailed validated intimate partner violence scales were used, while our intimate partner violence prevalence was obtained on the basis of two screening questions that did not include the range of women's experiences of intimate partner violence [16].

Further, this study reports on the co-occurrence of different types of intimate partner violence, and describes the association between past 12 months intimate sexual victimization experiences with demographic variables, partnership characteristics, suicidal behaviour and hazardous alcohol use. In this study of women with intimate partner violence attending antenatal care or general hospital out-patient services a moderate prevalence of sexual assault was found, which seem lower than in similar previous studies [2, 3, 17-19]. The joint occurrence of psychological abuse, physical and sexual violence found in this study seemed also lower than in some previous studies [3]. The overlap between different types of intimate partner violence that often occur simultaneously seem to "confirm that intimate partner violence are often part of a broader pattern of controlling behaviour" [20]. In agreement with previous studies [14, 21, 22], in this study sexually assaulted women were also more likely to report threatening or attempting suicide. This finding highlights the 
Table 1 Sample characteristics

\begin{tabular}{|c|c|c|c|c|c|}
\hline \multirow[t]{2}{*}{ Variable } & \multicolumn{2}{|c|}{$\begin{array}{l}\text { Total sample } \\
(N=207)\end{array}$} & \multirow{2}{*}{$\begin{array}{l}\text { Not sexually assaulted } \\
(n=150,72.5 \%)\end{array}$} & \multirow{2}{*}{$\begin{array}{l}\text { Sexually assaulted } \\
(n=57,27.5 \%) \\
M(S D)\end{array}$} & \multirow[t]{2}{*}{$P$-Value } \\
\hline & M & SD & & & \\
\hline Age (range 18-49) & 26.8 & 9.3 & $25.9(9.2)$ & $29.1(9.4)$ & 0.019 \\
\hline Number of children (range 0-4) & 1.1 & 1.0 & $0.9(1.0)$ & $1.4(1.0)$ & 0.005 \\
\hline \multicolumn{6}{|l|}{ Formal education } \\
\hline Primary or less & 54 & 26.2 & $35(23.3)$ & 19 (33.9) & \multirow[t]{3}{*}{0.253} \\
\hline Secondary & 109 & 52.9 & $84(56.0)$ & $25(44.6)$ & \\
\hline Post secondary & 43 & 20.9 & $31(20.7)$ & $12(21.4)$ & \\
\hline \multicolumn{6}{|l|}{ Recruitment } \\
\hline General out-patient clinic & 69 & 33.3 & $41(59.4)$ & $28(40.6)$ & \multirow[t]{2}{*}{0.003} \\
\hline Antenatal care clinic & 138 & 66.7 & $109(79.0)$ & $29(21.0)$ & \\
\hline Currently employed & 89 & 51.1 & $64(49.6)$ & $25(55.6)$ & 0.492 \\
\hline \multicolumn{6}{|l|}{ Economic household situation } \\
\hline Low & 75 & 36.8 & $55(37.2)$ & $20(35.7)$ & \multirow[t]{2}{*}{0.848} \\
\hline High & 129 & 63.2 & $93(62.8)$ & $36(64.3)$ & \\
\hline \multicolumn{6}{|l|}{ Marital status } \\
\hline Married/cohabitating & 180 & 87.0 & $133(88.7)$ & $47(82.5)$ & \multirow[t]{2}{*}{0.236} \\
\hline Single/divorced/separated & 27 & 13.0 & $17(11.3)$ & $10(17.5)$ & \\
\hline Currently living with perpetrator & 168 & 84.4 & $126(85.7)$ & $42(80.8)$ & 0.398 \\
\hline Left partner in the past 12 months & 18 & 8.7 & $11(7.3)$ & $7(12.3)$ & 0.275 \\
\hline \multicolumn{6}{|l|}{ Other types of intimate partner violence } \\
\hline \multicolumn{6}{|l|}{ Psychological abuse } \\
\hline Low (0-2) & 76 & 36.7 & $64(84.2)$ & $12(15.8)$ & \multirow[t]{3}{*}{$<0.001$} \\
\hline Medium (3-6) & 64 & 30.9 & $54(84.4)$ & $10(15.6)$ & \\
\hline High (7 or more) & 67 & 32.4 & $32(47.8)$ & $35(52.2)$ & \\
\hline \multicolumn{6}{|l|}{ Physical violence } \\
\hline Low $(0-1)$ & 86 & 41.7 & $73(84.9)$ & $13(15.1)$ & \multirow[t]{3}{*}{$<0.001$} \\
\hline Medium (2-6) & 53 & 25.7 & $40(75.5)$ & $13(24.3)$ & \\
\hline High (7 or more) & 67 & 32.5 & $37(55.2)$ & $30(44.8)$ & \\
\hline \multicolumn{6}{|l|}{ Danger } \\
\hline Low $(0-1)$ & 112 & 54.1 & $95(63.3)$ & $17(29.8)$ & \multirow[t]{3}{*}{$<0.001$} \\
\hline Medium (2-3) & 36 & 17.4 & $26(17.3)$ & $10(17.5)$ & \\
\hline High (4 or more) & 59 & 28.5 & $29(19.3)$ & $30(52.6)$ & \\
\hline \multicolumn{6}{|l|}{ Suicidal behaviour and alcohol use } \\
\hline $\begin{array}{l}\text { Suicidal behaviour (threat or attempt) } \\
\text { in the past } 12 \text { months }\end{array}$ & 36 & 17.6 & $16(10.8)$ & $20(35.7)$ & $<0.001$ \\
\hline
\end{tabular}

importance of mental health management, particularly regarding suicidal behaviour, and history of sexual assault [23].

The investigation found that in bivariate analysis that of the types of violence (psychological abuse, physical violence and danger) and in multivariable analysis that physical violence was associated with sexual assault. Similar results were found in previous studies [3, 12, 18, 24, 25]. McFarlane et al. [12] argue that higher scores of psychological abuse and physical violence for sexually assaulted women support a continuum of aggression theory. In particular, specific physical and psychological violent behaviour such as an increase in severity or frequency of physical violence, the use of a weapon, threat to kill, choking, illegal drug use, violence and constantly jealous, control of daily activities, spying, and having been beaten while pregnant were found in this study to be more frequent among sexually assaulted compared to 
Table 2 Types and frequency of sexual assault among sexually assaulted women $(N=57)$ in the past 12 months

\begin{tabular}{|c|c|c|c|c|}
\hline \multirow[t]{2}{*}{ Sexual assault } & Once or more & Once & $2-3$ times & 4 or more times \\
\hline & N (\%) & N (\%) & N (\%) & N (\%) \\
\hline 1. Demanded sex whether you wanted to or not? & $50(87.7)$ & $17(29.8)$ & $14(24.6)$ & $19(14.0)$ \\
\hline 2. Made you have oral sex against your will? & $18(31.6)$ & $4(7.0)$ & $8(14.0)$ & $6(10.5)$ \\
\hline 3. Made you have sexual intercourse against your will? & $33(57.9)$ & $9(15.8)$ & $12(21.1)$ & $12(21.1)$ \\
\hline 4. Physically forced you to have sex? & $24(42.1)$ & $7(12.3)$ & $6(10.5)$ & $11(19.3)$ \\
\hline 5. Made you have anal sex against your will? & $17(29.7)$ & $7(12.3)$ & $6(10.5)$ & $4(7.0)$ \\
\hline 6. Used an object on you in a sexual way? & $6(10.5)$ & $3(5.3)$ & $3(5.3)$ & $0(0.0)$ \\
\hline
\end{tabular}

non-sexually assaulted women. Information on acts of physical and psychological violence that are more likely to co-occur with sexual assault has important implications for legal investigations [24].

In bivariate analysis, the study found, in agreement with other studies [2, 21, 22] that sexually assaulted women reported statistically significant more risk factors for danger or femicide. Of concern was the finding that almost half of sexually assaulted women had received death threats by their intimate partners. The study found a high prevalence of hazardous drinking or having an alcohol use disorder, but this was not associated with sexual assault victimization, as found in some previous studies $[2,12]$. A few of the women had left the partner in the past 12 months, which seemed not to have significantly reduced sexual intimate partner violence.

\section{Study limitations}

The results of this study cannot be generalized to all female survivors of intimate partner violence in Thailand

Table 3 Frequencies of not sexually abused and sexually abused women who reported "Yes" to risk factor for danger within preceding 12 months days and Relative Risk (95\% Confidence Interval)

\begin{tabular}{|c|c|c|c|}
\hline \multirow[t]{2}{*}{ By sexual abuse group } & \multirow{2}{*}{$\begin{array}{l}\text { Not sexually assaulted } \\
(N=150) \\
N(\%)\end{array}$} & \multirow{2}{*}{$\begin{array}{l}\text { Sexually assaulted } \\
(N=57) \\
N(\%)\end{array}$} & \multirow[t]{2}{*}{$\begin{array}{l}\text { Relative Risk Ratio (95\% } \\
\text { Confidence Interval) }\end{array}$} \\
\hline & & & \\
\hline $\begin{array}{l}\text { 1. Has the physical violence increased in severity or frequency } \\
\text { in the past } 12 \text { months? }\end{array}$ & $29(19.3)$ & $25(43.9)$ & $1.47(1.14-1.91)^{*}$ \\
\hline 2. Does he own a gun? & $13(8.7)$ & $5(8.8)$ & $1.00(0.74-1.35)$ \\
\hline $\begin{array}{l}\text { 3. Has he ever used a weapon against you or threatened you } \\
\text { with a lethal weapon } 12 \text { months? }\end{array}$ & $10(6.7)$ & $15(26.3)$ & $1.92(1.18-3.13)^{*}$ \\
\hline 4. Does he threaten to kill you? & $36(24.0)$ & $26(45.6)$ & $1.35(1.08-1.70)^{*}$ \\
\hline $\begin{array}{l}\text { 5. Has he avoided being arrested for domestic violence in } \\
\text { the past } 12 \text { months? }\end{array}$ & $8(5.3)$ & $7(12.3)$ & $1.38(0.86-2.24)$ \\
\hline 6. Does he ever try to choke you? & $20(13.3)$ & $17(29.8)$ & $1.42(1.04-1.93)^{*}$ \\
\hline $\begin{array}{l}\text { 7. Does he use illegal drugs in the past } 12 \text { months? By } \\
\text { drugs, I mean "marihuana" or street drugs such as } \\
\text { amphetamines ('ya-baa'), ecstasy ('ya E'), cocaine, "crack" }\end{array}$ & $13(8.7)$ & $11(19.3)$ & $1.38(0.95-2.02)$ \\
\hline 8. Is he an alcoholic or problem drinker? & $44(29.3)$ & $18(31.6)$ & $1.03(0.85-1.24)$ \\
\hline $\begin{array}{l}\text { 9. Does he control most or all of your daily activities in } \\
\text { the past } 12 \text { months? }\end{array}$ & $24(16.0)$ & $24(42.1)$ & $1.59(1.18-2.13)^{*}$ \\
\hline 10. Is he violently and constantly jealous of you? & $41(27.3)$ & $29(50.9)$ & $1.26(1.10-1.68)^{*}$ \\
\hline $\begin{array}{l}\text { 11. Have you ever been beaten by him while you were } \\
\text { pregnant in the past } 12 \text { months? }\end{array}$ & $28(18.7)$ & $19(33.3)$ & $1.28(1.00-1.65)^{*}$ \\
\hline $\begin{array}{l}\text { 12. Has he ever threatened or tried to commit suicide } \\
\text { in the past } 12 \text { months? }\end{array}$ & $9(6.0)$ & $4(7.0)$ & $1.05(0.72-1.52)$ \\
\hline 13. Does he threaten to harm your children? & $9(6.0)$ & $7(12.3)$ & $1.31(0.85-2.04)$ \\
\hline $\begin{array}{l}\text { 14. Does he follow or spy on you, leaves threatening } \\
\text { notes or messages, destroys your property, or calls you } \\
\text { when you don't want him to? }\end{array}$ & $36(24.0)$ & $30(52.6)$ & $1.48(1.17-1.87)^{*}$ \\
\hline Danger scale, M (SD) & $2.1(3.1)$ & $4.2(3.6)$ & ${ }^{1} P<0.001$ \\
\hline
\end{tabular}

*Significantly different at $P<0.05 ;{ }^{1}$ Mann-Whitney $\mathrm{U}$ test 
Table 4 Predictors of sexual assault

\begin{tabular}{|c|c|c|c|c|}
\hline Variable & UOR $(95 \% \mathrm{Cl})$ & P-value & $\operatorname{AOR}(95 \% \mathrm{Cl})^{\mathrm{a}, \mathrm{b}}$ & P-value \\
\hline \multicolumn{5}{|l|}{ Demographics and partner characteristics } \\
\hline Age in years & $1.04(1.00-1.07)$ & 0.033 & - & \\
\hline \multicolumn{5}{|l|}{ Formal education } \\
\hline Primary or less & 1 (Reference) & & - & \\
\hline Secondary & $0.55(0.27-1.12)$ & 0.099 & & \\
\hline Post secondary & $0.71(0.30-1.70)$ & 0.446 & & \\
\hline \multicolumn{5}{|l|}{ Recruitment } \\
\hline Antenatal care clinic & 1 (Reference) & & 1 (Reference) & \\
\hline General out-patient clinic & $2.57(1.37-5.83)$ & 0.003 & $1.46(0.57-3.75)$ & 0.431 \\
\hline Number of children & $1.57(1.14-2.15)$ & 0.006 & $1.31(0.79-2.19)$ & 0.294 \\
\hline Currently employed & $1.27(0.64-2.51)$ & 0.493 & - & \\
\hline \multicolumn{5}{|l|}{ Economic household situation } \\
\hline Low & 1 (Reference) & & - & \\
\hline High & $0.94(0.50-1.78)$ & 0.848 & & \\
\hline \multicolumn{5}{|l|}{ Marital status } \\
\hline Married/cohabitating & 1 (Reference) & & - & \\
\hline Single/divorced/separated & $1.60(0.26-1.40)$ & 0.239 & & \\
\hline Currently living with the perpetrator & $0.70(0.31-1.61)$ & 0.400 & - & \\
\hline Left partner in the past 12 months & $1.77(0.65-4.82)$ & 0.264 & - & \\
\hline \multicolumn{5}{|l|}{ Other types of intimate partner violence } \\
\hline \multicolumn{5}{|l|}{ Psychological abuse } \\
\hline Low (0-2) & 1 (Reference) & & 1 (Reference) & \\
\hline Medium (3-6) & $0.99(0.40-2.46)$ & 0.979 & $0.74(0.27-2.07)$ & 0.568 \\
\hline High (7 or more) & $5.83(2.67-12.74)$ & $<0.001$ & $3.42(1.07-11.01)$ & 0.039 \\
\hline \multicolumn{5}{|l|}{ Physical violence } \\
\hline Low $(0-1)$ & 1 (Reference) & & 1 (Reference) & \\
\hline Medium (2-6) & $1.83(0.77-4.31)$ & 0.170 & $1.80(0.69-4.93)$ & 0.233 \\
\hline High (7 or more) & $4.55(2.13-9.75)$ & $<0.001$ & $2.42(0.95-6.16)$ & 0.064 \\
\hline \multicolumn{5}{|l|}{ Danger } \\
\hline Low $(0-1)$ & 1 (Reference) & & 1 (Reference) & \\
\hline Medium (2-3) & $3.13(1.33-7.38)$ & 0.009 & $1.16(0.38-3.55)$ & 0.794 \\
\hline High (4 or more) & $8.49(3.75-19.18)$ & $<0.001$ & $2.03(0.65-6.36)$ & 0.226 \\
\hline Suicidal behaviour in the past 12 months & $4.58(2.16-9.74)$ & $<0.001$ & $2.62(0.94-7.31)$ & 0.065 \\
\hline
\end{tabular}

UOR Unadjusted Odds Ratio, AOR Adjusted Odds Ratio, Cl Confidence Interval

a Logistic regression, using forced entry; ${ }^{\mathrm{b}}$ Hosmer $\&$ Lemeshow Chi-square $=9.96, P=0.268$; Nagelkerke $\mathrm{R}^{2}: 0.30$

since the current study recruited antenatal care and general out-patients in one region. Further, the study relied on self-reports which may under- or overreport due to lack of adequate recall or lack of voluntary disclosure [2]. Sexual assault was assessed in face-to-face interviews, which may have led to more under-reporting than in self-report questionnaires [26]. Some other studies $[8,20,26]$ have found that the assessment of injury resulting from intimate partner violence and the experience of early violence (such as childhood sexual abuse) added an important dimension of intimate partner violence, which should be added in future research.

\section{Conclusions}

The study found a moderate rate of sexual assault in intimate violent partner relationships and those sexual assaults are more likely to co-occur with physical intimate partner violence and suicidal behaviour. This knowledge may be helpful in the detection and management of sexual assault in intimate violent partner relationships of women in health care settings in Thailand. 


\section{Abbreviations}

AUDIT-C: Alcohol Use Disorder Identification Test- Consumption; IPV: Intimate Partner Violence; OSCC: One-Stop Crisis Centre; SVAWS: Severity of Violence Against Women Scale

\section{Acknowledgements}

We thank Professors Nanthana Thananowan and Judith McFarlane for their input in the study design.

\section{Funding}

This project was supported by Mahidol University. The funding body did not play any role in the design of the study and collection, analysis, and interpretation of data and in writing of the manuscript.

\section{Availability of data and materials}

The data for the current study will not be shared publicly as participants were informed at the time of providing consent that only researchers involved in the project would have access to the information they provided.

\section{Authors' contributions}

$\mathrm{SP}, \mathrm{KP}, \mathrm{OL}$ and KS conceived and designed the study. Data collection was coordinated by SP, OL and KS. Analysis was performed by KP and SP and the text was drafted by SP and KP. All authors reviewed, made critical revision and approved the final text.

\section{Ethics approval and consent to participate}

The study was performed according to the principles of the Declaration of Helsinki.

The study protocol was approved by the Office of the Committee for Research Ethics (Social Sciences), Faculty of Social Sciences and Humanities, Mahidol University (COA. No.: 2014/328.2511). Written informed consent was obtained from all participants.

\section{Consent for publication}

Not applicable.

\section{Competing interests}

The authors declare that they have no competing interests.

\section{Publisher's Note}

Springer Nature remains neutral with regard to jurisdictional claims in published maps and institutional affiliations.

\section{Author details}

'ASEAN Institute for Health Development, Mahidol University, Salaya, Phutthamonthon, Nakhonpathom 73170, Thailand. '2Department of Research \& Innovation, University of Limpopo, Sovenga 0727, South Africa. ${ }^{3}$ HIV/AIDS/ STI/and TB (HAST), Human Sciences Research Council, Pretoria 0001, South Africa.

Received: 16 December 2015 Accepted: 28 January 2018

Published online: 06 February 2018

\section{References}

1. Krug EG, Dahlberg LL, Mercy JA, Zwi AB, Lozano R, editors. World report on violence and health. Geneva: World Health Organization; 2002.

2. McFarlane J, Malecha A, Gist J, Watson K, Batten E, Hall I, Smith S. Intimate partner sexual assault against women and associated victim substance use, suicidality, and risk factors for femicide. Issues Men Health Nurs. 2005;26(9):953-67.

3. Pengpid S, Peltzer K. Sexual assault and other types of intimate partner violence in women with protection orders in Vhembe District, South Africa. Violence Vict. 2014;29(5):857-71

4. Lukasse M, Schroll AM, Ryding EL, Campbell J, Karro H, Kristjansdottir H, Laanpere M, Steingrimsdottir T, Tabor A, Temmerman M, Van Parys AS, Wangel AM, Schei B. Prevalence of emotional, physical and sexual abuse among pregnant women in six European countries. Acta Obstet Gynecol Scand 2014 Jul;93(7):669-677. doi: https://doi.org/10.1111/aogs.12392.

5. Devries KM, Kishor S, Johnson H, Stöckl H, Bacchus L, Garcia-Moreno C, Watts C. Intimate partner violence during pregnancy: analysis of prevalence data from 19 countries. Reprod Health Matters. 2010;18(36):158-70. https:// doi.org/10.1016/S0968-8080(10)36533-5.
6. Thananowan N, Heidrich SM. Intimate partner violence among pregnant Thai women. Violence Against Women. 2008;14(5):509-27.

7. Saito A, Creedy D, Cooke M, Chaboyer W. Effect of intimate partner violence on antenatal functional health status of childbearing women in northeastern Thailand. Health Care Women Int. 2013;34(9):757-74.

8. Saito A, Creedy D, Cooke M, Chaboyer W. Effect of intimate partner violence on postpartum women's health in northeastern Thailand. Nurs Health Sci. 2012;14(3):345-51.

9. McFarlane J, Parker B, Soeken K, Bullock L. Abuse assessment screen (A.A.S.) JAMA. 1992;267:3176-8.

10. World Health Organization (WHO). Putting women's safety first: ethical and safety recommendations for research on domestic violence against women. Geneva: WHO; 1999.

11. Marshall LL. Development of the severity of violence against women scales. J Fam Viol. 1992;7:103-21.

12. McFarlane J, Wiist W, Watson M. Characteristics of sexual abuse against pregnant Hispanic women by their male partners. J Women's Health. 1998; 7(6):739-45.

13. Scricamsuk A. Domestic violence against pregnant women: A Thai perspective, 2006. PhD Thesis, School of Nursing and Midwifery, Griffith Health at Griffith University, Australia. Available at https://www120.secure.griffith.edu.au/rch/file/ c0973efd-57e3-525b.../02Whole.pdf. Accessed 10 Oct 2015.

14. Campbell JC. Nursing assessment for risk of homicide with battered women. Adv Nurs Sci. 1986:8(4):36-51.

15. Bush K, Kivlahan DR, McDonell MB, Fihn SD, Bradley KA. The AUDIT alcohol consumption questions (AUDIT-C): an effective brief screening test for problem drinking. Arc Intern Med. 1998;158:1789-95.

16. O'Doherty L, Hegarty K, Ramsay J, Davidson LL, Feder G, Taft A. Screening women for intimate partner violence in healthcare settings. Cochrane Database Syst Rev. 2015;22(7):CD007007. https://doi.org/10.1002/14651858.CD007007.

17. Cole J, Logan TK, Shannon L. Intimate sexual victimization among women with protective orders: types and associations of physical and mental health problems. Violence Victims. 2005:20(6):695-715.

18. Zacarias AE, Macassa G, Svanström L, Soares JJ, Antai D. Intimate partner violence against women in Maputo city, Mozambique. BMC Int Health Hum Rights. 2012;12:35. https://doi.org/10.1186/1472-698X-12-35.

19. Dunkle KL, Jewkes RK, Brown HC, Yoshihama M, Gray GE, Mclntyre JA Harlow SD. Prevalence and patterns of gender- based violence and revictimization among women attending antenatal clinics in Soweto, South Africa. Am J Epidemiol. 2004;160(3):230-9.

20. Kerley KR, Xu X, Sirisunyaluck B. Self-control, intimate partner abuse, and intimate partner victimization: testing the general theory of crime in Thailand. Deviant Behavior. 2008;29:503-32.

21. Coker AL, Smith PH, Bethea L, King MR, McKeown RE. Physical health consequences of physical and psychological intimate partner violence. Arc Fam Med. 2000;9(5):451-7.

22. Ishida K, Stupp P, Melian M, Serbanescu F, Goodwin M. Exploring the associations between intimate partner violence and women's mental health: evidence from a population-based study in Paraguay. Soc Sci Med. 2010;71(9):1653-61.

23. Alsaker K, Morken T, Baste V, Campos-Serna J, Moen BE. Sexual assault and other types of violence in intimate partner relationships. Acta Obstet Gynecol Scand. 2012;91(3):301-7.

24. Bennice JA, Resick PA, Mechanic M, Astin M. The relative effects of intimate partner physical and sexual violence on post-traumatic stress disorder symptomatology. Violence Vict. 2003;18(1):87-94.

25. Swanberg J, Macke C, Logan TK. Working women making it work: intimate partner violence, employment, and workplace support. J Interpers Violence. 2007:22:292-311.

26. Mechanic MB, Weaver TL, Resick PA. Mental health consequences of intimate partner abuse: a multidimensional assessment of four different forms of abuse. Violence Against Women. 2008;14(6):634-54. 